\title{
A population-based analysis of breast cancer incidence and survival by subtype in Ontario women
}

\author{
S.J. Seung HonBSc, ${ }^{*}$ A.N. Traore MD MSc, B. Pourmirza MD, ${ }^{+}$K.E. Fathers $\mathrm{PhD}^{+}$ \\ M. Coombes $\mathrm{MSc}^{\neq}$and K.J. Jerzak MD MSc${ }^{\S}$
}

\begin{abstract}
Background Breast cancer (вСа) is the type of cancer most frequently diagnosed among women in Canada. Breast cancer is categorized into various molecular subtypes by the expression of estrogen receptor (ER), progesterone receptor (PgR), and HER2 (human epidermal growth factor receptor 2). Currently, Canada has no national cancer registry with epidemiology data by subtype. Thus, we conducted a study to determine incidence, survival, and clinicopathologic characteristics by BCa subtype [triple negative breast cancer (TNBC); HER2+; and hormone receptor-positive (HR+), HER2-] in Canadian women newly diagnosed with BCa.
\end{abstract}

Methods Female patients diagnosed between 1 April 2012 and 31 March 2016 (fiscal 2012-2015) were identified in the Ontario Cancer Registry, and individual patient data were linked to data in provincial health administrative databases. Descriptive statistics and Kaplan-Meier curves were generated.

Results In this cohort, 3277 women (9.5\%) had TNBC, 4902 (14.3\%) had HER2+ BCa, and 22,247 (64.8\%) had HR+, HER2breast cancer. The annual incidence was 15 per 100,000 for the TNBC group, 21-23 per 100,000 for the HER $2+$ group, and 97-105 per 100,000 for the HR+, HER2- group. The lowest median overall survival (mOs) of 8.9 months was observed in women with clinical stage IV TNBC. In comparison, the mOS was 37.3 months in those with HER2+ disease and 35.2 months in those with and HR+, HER2- metastatic BCa.

Conclusions In the present study, the most recent and largest administrative database analysis of a Canadian population to date, we observed a subtype distribution consistent with previously reported data, together with comparable annual incidence and overall survival patterns.

Key Words Breast cancer, subtypes; incidence; overall survival; epidemiology

Curr Oncol. 2020 April:27(2)e191-e198

www.current-oncology.com

\section{INTRODUCTION}

For women in Canada, breast cancer (BCa) is the most frequently diagnosed type of cancer (excludingnon-melanoma skin cancers). In 2017, an estimated 26,300 Canadian women were diagnosed with BCa, and an estimated 4900 died of the disease $\mathrm{e}^{1}$. Breast cancer is routinely categorized into a number of different molecular subtypes that are identified by gene expression profiling ${ }^{2,3}$ and immunohistochemistry $^{4}$. In the literature, BCa is commonly divided into the luminal A, luminal B, HER2 (human epidermal growth factor receptor 2)-enriched, and basal types. Given that
Ki-67, epidermal growth factor receptor, and cytokeratin 7 testing are not routinely used in Canada and many other countries around the world, the вса subtypes are generally categorized as hormone receptor positive (HR+), based on expression of estrogen receptor (ER) or progesterone receptor (PgR), or both ${ }^{5-7}$; HER2-positive (HER2+), regardless of HR status; or triple-negative (TNBC), lacking expression of HER2, ER, and PgR. Those subtypes of BCa each have distinct biologic and clinical characteristics, including differences in risk factors, disease management, recurrence rates, and survival outcomes ${ }^{8,9}$. A personalized treatment approach is required based on the patient's specific BCa subtype ${ }^{10-12}$. 
Approximately $15 \%-20 \%$ of BCa is triple-negative and $20 \%$ is HER $2+$; most are HR+, HER2-13-16. Historically, longer survival has been reported for patients with HR+, HER2- BCa than for those with TNBC or HER2+ disease ${ }^{17-19}$. However, a recent study of almost 160,000 U.S. patients diagnosed with BCa between 2010 and 2013 found that median overall survival (mos) was longer for those with metastatic HER2+ BCa than for those with HR+, HER2- disease (44 months vs. 36 months); patients with metastatic TNBC had the shortest mos, at 13 months ${ }^{20}$. The superior outcomes of patients with metastatic HER2+ BCa in that study can be explained by the availability of very effective HER2-targeted therapies, including trastuzumab and pertuzumab (in combination with taxanes in the first-line metastatic setting), trastuzumab emtansine, and lapatinib plus capecitabine ${ }^{21}$. However, with the recent introduction of inhibitors of cyclin-dependent kinases 4 and 6 for patients with metastatic HR+, HER2- BCa, it is possible that those trends will change in the near future. In contrast, patients with metastatic TNBC have consistently been reported to have a shorter life expectancy, largely because of the lack of targeted and effective systemic therapies.

To date, population-based epidemiologic studies of BCa subtypes have largely focused on small observational cohorts or particular geographic regions, mostly outside of Canada ${ }^{22-24}$. From a Canadian perspective, studies of incidence and survival in women by BCa subtype have been limited ${ }^{1,25}$. The objective of the present study was to determine the clinicopathologic characteristics, incidence, and overall survival (OS) of women newly diagnosed with BCa in Ontario during fiscal years 2012-2015, based on BCa subtype.

\section{METHODS}

\section{Study Design and Setting}

This population-based retrospective study identified women newly diagnosed with BCa in Ontario between 1 April 2012 and 31 March 2016 (fiscal years 2012-2015) through the Ontario Cancer Registry (OCR). All data, including OCR data, were obtained from data holdings at ICES (formerly the Institute for Clinical Evaluative Sciences). The not-for-profit ICES research institute encompasses a community of research, data, and clinical experts, and holds a secure and accessible array of Ontario's health-related data. Research ethics approval for this study was granted by Advarra's Canadian institutional review board.

\section{Patient Cohort}

Ontario has a resident population of 14.2 million and provides publicly funded health care services through OHIP, the Ontario Health Insurance Plan. To conduct analyses of real-world data, ICES combines OHIP with other population-level health information based on encrypted patient identifiers.

For the present study, women with an initial primary diagnosis of BCa were identified in the OCR using the International Statistical Classification of Diseases and Related Health Problems (10th revision) diagnosis code C50x (female, right and left breasts). Women whose information was available within the follow-up period (until 31 March 2017) were included in the study cohort. Exclusion criteria included a concurrent cancer diagnosis, previous diagnosis of any other cancer, diagnosis of malignant lymphoma of the breast, non-Ontario resident, male or missing sex, missing age, age less than 18 or greater than 105 years, and BCa diagnosis after the date of death because of entry error. The BCa subtype, tumour size, and grade were characterized from the OCR. The BCa subtypes analyzed in this study were defined as follows: TNBC (ER-, PgR-, HER2-); HER2+ (HR+ or HR-); and HR+, HER2-. We did not discriminate between weak ER+ or PgR+ compared with less than $1 \%$ ER or PgR expression because the latter was the "gold standard" 26 for the diagnosis of TNBC at the time of data collection between 2012 and 2016. Further, that definition of TNBC $(<1 \%$ ER or PgR expression, and HER2- status) still applies today.

\section{Statistical Analysis}

Descriptive statistics (means, medians, standard deviations, interquartile ranges) were used to evaluate the study cohort by subtype, but $t$-tests were not conducted to determine statistical significance. The results are reported at an aggregate level and tabulated. Demographic characteristics, including neighborhood income quintile, were obtained using the Registered Persons Database. Score on the Charlson comorbidity inde ${ }^{27}$ was calculated using inpatient admission records, with a lookback period of 2 years before the BCa diagnosis. Annual incidence of BCa was calculated by dividing the number of newly diagnosed BCa cases in the OCR for each fiscal year by the number of adult Ontario women at risk (excluding women previously diagnosed with BCa) based on an ICES-derived cohort of approximately 5-6 million women who were alive and eligible to receive health insurance through OHIP, and who experienced at least 1 encounter during the follow-up period (supplemental Table 1). Thus, annual incidence is reported per 100,000 women at risk. For survival outcomes, 1-year follow-up was used (survival rates and mos); os was defined as time from diagnosis to date of death (for women with a known date of death). Women alive or lost to follow-up at the end of the study period (31 March 2017) were censored. Kaplan-Meier curves were generated to present median, 1-year, and 5-year os rates for each BCa subtype. The SAS Enterprise Guide software application (version 7.15: SAS Institute, Cary, NC, U.S.A.) was used in this analysis.

\section{RESULTS}

\section{Baseline Patient and Tumour Characteristics}

During fiscal years 2012-2015, 34,340 women ("all cases") diagnosed with BCa met the study inclusion criteria (Table I). In that cohort, the distribution by вCa subtype was $64.8 \%$ HR+, HER $2-$; $14.3 \%$ HER $2+$; and $9.5 \%$ TNBC. In $11.4 \%$, subtype was unknown, and so that group of women was excluded from further analyses.

Mean age at diagnosis was similar regardless of BCa subtype, although women with HER2+ BCa were slightly younger ( 57.8 years) than those with TNBC ( 59.1 years) and those with HR+, HER2- BCa (62.1 years). Most women were diagnosed with stage I or II disease $(78.0 \%)$; however, at diagnosis, tumours tended to be larger in women with TNBC and HER $2+$ BCa ( $>3 \mathrm{~cm}: 41.9 \%$ and $38.9 \%$ respectively) than in those with HR+, HER2- BCa (25.4\%). In addition, 
presentation with stage IV disease was slightly more likely in women with HER $2+$ BCa $(7.2 \%)$ than in those with TNBC (5.8\%) or HR+, HER $2-$ BCa $(3.7 \%)$. Tumours were also more likely to be lymph node-positive in women with HER2+ BCa
$(42.6 \%)$ than in those with TNBC $(33.0 \%)$ or HR+, HER2- BCa $(32.2 \%)$. Interestingly, presentation with lymph nodepositive tumours was more likely among younger women (<65 years: $44.9 \%$ HER $2+; 37.2 \%$ HR+, HER $2-; 34.7 \%$ TNBC) than

TABLE I Baseline patient and disease characteristics

\begin{tabular}{|c|c|c|c|c|}
\hline \multirow[t]{2}{*}{ Characteristic } & \multicolumn{4}{|c|}{ Disease subtype } \\
\hline & Overall & TNBC & HER2+ & HR+, HER2- \\
\hline Patients $(n)$ & $34,340^{\mathrm{a}}$ & 3,277 & 4,902 & 22,247 \\
\hline Mean age (years) & $61.5 \pm 13.8$ & $59.1 \pm 14.6$ & $57.8 \pm 13.5$ & $62.1 \pm 13.2$ \\
\hline \multicolumn{5}{|l|}{ Age group $[n(\%)]$} \\
\hline 18-34 Years & $684(2.0)$ & $140(4.3)$ & $157(3.2)$ & $291(1.3)$ \\
\hline 35-49 Years & 6,295 (18.3) & $729(22.2)$ & $1,249(25.5)$ & $3,727(16.8)$ \\
\hline 50-64 Years & $13,027(37.9)$ & $1,196(36.5)$ & $1,986(40.5)$ & $8,485(38.1)$ \\
\hline 65-74 Years & 8,247 (24.0) & $700(21.4)$ & $904(18.4)$ & $5,798(26.1)$ \\
\hline 75-84 Years & 4,217 (12.3) & $367(11.2)$ & $445(9.1)$ & $2,854(12.8)$ \\
\hline$\geq 85$ Years & $1,870(5.4)$ & $145(4.4)$ & $161(3.3)$ & 1,092 (4.9) \\
\hline \multicolumn{5}{|l|}{ Disease stage $[n(\%)]$} \\
\hline 0 & $86(0.3)$ & $0(0.0)$ & $0(0.0)$ & $1-5^{b}$ \\
\hline I & $13,989(40.7)$ & $910-914^{b}$ & $1,412(28.8)$ & $10,469(47.1)$ \\
\hline II & 12,819 (37.3) & $1,608(49.1)$ & $2,107(43.0)$ & $8,232(37.0)$ \\
\hline III & 4,508 (13.1) & $559-563^{b}$ & $1,016(20.7)$ & $2,657-2,662^{b}$ \\
\hline IV & $1,673(4.9)$ & $190(5.8)$ & $354(7.2)$ & 813 (3.7) \\
\hline Unknown & $1,265(3.7)$ & $6(0.2)$ & $13(0.3)$ & $71(0.3)$ \\
\hline \multicolumn{5}{|l|}{ Score on the $\mathrm{CCl}$} \\
\hline Mean & $0.64 \pm 1.20$ & $0.60 \pm 1.18$ & $0.61 \pm 1.22$ & $0.61 \pm 1.15$ \\
\hline Median & 0 & 0 & 0 & 0 \\
\hline IQR & $0-1$ & $0-1$ & $0-1$ & $0-1$ \\
\hline \multicolumn{5}{|l|}{$\mathrm{CCl}$ score group $[n(\%)]$} \\
\hline $0-5$ & $10,708(31.2)$ & $993(30.3)$ & 1,353 (27.6) & $6,927(31.1)$ \\
\hline $6-10$ & $187(0.5)$ & $16(0.5)$ & $31(0.6)$ & $92(0.4)$ \\
\hline Missing & $23,445(68.3)$ & $2,268(69.2)$ & $3,518(71.8)$ & $15,228(68.4)$ \\
\hline \multicolumn{5}{|l|}{ Tumour size category [n (\%)] } \\
\hline No mass found & $70(0.2)$ & $11(0.3)$ & $13(0.3)$ & $14(0.1)$ \\
\hline$<1 \mathrm{~cm}$ & 4,822 (14.0) & $231(7.0)$ & $542(11.1)$ & $3,451(15.5)$ \\
\hline $1 \mathrm{~cm}$ to $<2 \mathrm{~cm}$ & $10,264(29.9)$ & 775 (23.6) & $1,133(23.1)$ & $7,907(35.5)$ \\
\hline $2 \mathrm{~cm}$ to $<3 \mathrm{~cm}$ & 7,404 (21.6) & $825(25.2)$ & $1,195(24.4)$ & $4,989(22.4)$ \\
\hline $3 \mathrm{~cm}$ to $<4 \mathrm{~cm}$ & $3,850(11.2)$ & $568(17.3)$ & $736(15.0)$ & $2,325(10.5)$ \\
\hline $4 \mathrm{~cm}$ to $<5 \mathrm{~cm}$ & $1,916(5.6)$ & $302(9.2)$ & $371(7.6)$ & $1,124(5.1)$ \\
\hline$\geq 5 \mathrm{~cm}$ & $3,710(10.8)$ & $503(15.3)$ & $800(16.3)$ & 2,195 (9.9) \\
\hline Other $^{\mathrm{c}}$ & $2,304(6.7)$ & $62(1.9)$ & $112(2.3)$ & $242(1.1)$ \\
\hline \multicolumn{5}{|l|}{ Nodal status $[n(\%)]$} \\
\hline Positive & $10,787(31.4)$ & $1,082(33.0)$ & 2,087 (42.6) & $7,153(32.2)$ \\
\hline Negative & $18,637(54.3)$ & $1,941(59.2)$ & $2,442(49.8)$ & $13,248(59.5)$ \\
\hline Unknown & 4,916 (14.3) & $254(7.8)$ & $373(7.6)$ & $1,846(8.3)$ \\
\hline \multicolumn{5}{|l|}{ Follow-up time (months) } \\
\hline Median & 33.1 & 30.7 & 32.5 & 33.9 \\
\hline IQR & $21.6-46.1$ & $19.4-44.7$ & $21.5-45.8$ & $22.4-46.5$ \\
\hline
\end{tabular}

a The "Overall" group includes 3914 patients with breast cancer of an unknown subtype; the sum of the 3 known breast cancer subtypes will not equal 34,340.

b Small-cell suppression or number ranges that contain values subject to small-cell suppression (required to prohibit "back calculation").

c Includes "other," "unknown," "missing."

$\mathrm{TNBC}=$ triple-negative breast cancer; HER2 = human epidermal growth factor receptor 2; $\mathrm{HR}=$ hormone receptor; $\mathrm{CCl}=\mathrm{Charlson}$ comorbidity index; $I Q R=25 \%-75 \%$ interquartile range. 
TABLE II Survival rates and median overall survival by breast cancer subtype and known stage

\begin{tabular}{|c|c|c|c|c|c|c|}
\hline \multirow[t]{2}{*}{ Subtype } & \multirow[t]{2}{*}{ Cases } & \multirow[t]{2}{*}{ Stage } & \multicolumn{2}{|c|}{ Survival ( $\%$ alive) at ... } & \multicolumn{2}{|c|}{ Median overall survival } \\
\hline & & & 1 Year & 5 Years & Months & $95 \% \mathrm{CI}$ \\
\hline \multirow[t]{4}{*}{ TNBC } & 3,277 & I & 98.8 & 93.3 & - & \\
\hline & & II & 97.6 & 78.9 & - & \\
\hline & & III & 90.2 & 47.2 & - & \\
\hline & & IV & 41.1 & 7.4 & 8.9 & 6.7 to 11.1 \\
\hline \multirow[t]{4}{*}{ HER2+ } & 4,902 & I & 99.6 & 96.5 & - & \\
\hline & & II & 98.6 & 87.5 & - & \\
\hline & & III & 96.4 & 79.9 & - & \\
\hline & & IV & 74.6 & 36.6 & 37.3 & 28.0 to 43.0 \\
\hline \multirow[t]{4}{*}{$\mathrm{HR}+$} & 22,247 & I & 99.4 & 94.7 & - & \\
\hline & & II & 98.7 & 88.1 & - & \\
\hline & & III & 96.0 & 72.9 & - & \\
\hline & & IV & 80.4 & 24.0 & 35.2 & 32.4 to 41.5 \\
\hline \multirow[t]{4}{*}{ All cases } & 32,989 & I & 99.3 & 94.1 & - & \\
\hline & & II & 98.3 & 86.3 & - & \\
\hline & & III & 95.0 & 70.8 & - & \\
\hline & & IV & 70.7 & 23.4 & 28.6 & 26.2 to 30.9 \\
\hline
\end{tabular}

$\mathrm{Cl}=$ confidence interval; $\mathrm{TNBC}=$ triple-negative breast cancer; HER2 = human epidermal growth factor receptor 2; HR = hormone receptor.

among older women ( $\geq 65$ years: $37.4 \%$ HER $2+; 25.7 \%$ HR+, HER2-;30.2\% TNBC; supplemental Table2). Comorbidity was difficult to assess because scores on the Charlson comorbidity index were missing in most patients for each subtype (>68\%). Median follow-up ranged from 30.7 months to 33.9 months for the various subtypes.

\section{Incidence}

For fiscal years 2012-2015, 30,426 women with BCa of a known subtype constituted the denominator for calculating the annual incidence (BCa cases per 100,000 women at risk) in Ontario for the cohort overall and by subtype (Figure 1). As expected, the incidence rate was highest for the HR+, HER2- subtype (97-105 per 100,000), followed by HER $2+$ (21-23 per 100,000$)$ and TNBC $(15$ per 100,000$)$. The incidence was generally consistent over the timeframe examined.

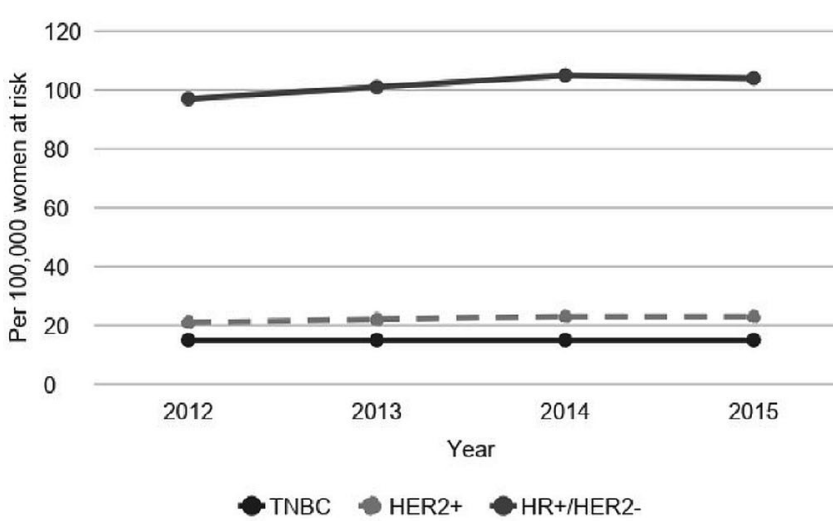

FIGURE 1 Annual breast cancer incidence per 100,000 women, by subtype. TNBC = triple negative breast cancer; HER2 = human epidermal growth factor receptor $2 ; \mathrm{HR}=$ hormone receptor.

\section{Overall Survival}

The 34,340 women with BCa in fiscal years 2012-2015 were used to determine survival estimates for the subtypes overall; the 32,989 women with BCa of a known subtype were used to determine survival as stratified by disease stage (I-IV) at diagnosis (Figure 2), thus excluding the 1351 women with either stage 0 or unknown-stage disease. KaplanMeier survival curves for each subtype [Figure 2(A-C)] consistently showed that more advanced stages of disease were associated with worse long-term outcomes. In addition, relative to the HER2+ and HR+, HER2- cohorts [Figure 2(B,C)], the TNBC cohort [Figure 2(A)] showed more pronounced differences in survival outcomes for the various stages.

For each BCa subtype, the 1-year and 5-year survival rates were both associated with disease stage (Table II). The mos was available only for women with metastatic or stage IV disease and not for those with early-stage BCa (I-III). Women with stage IV TNBC had the lowest mOS (8.9 months vs. 37.3 months for HER2+ BCa and 35.2 months for HR+, HER2- BCa).

\section{DISCUSSION}

This retrospective, population-level study identified a cohort of 34,340 women diagnosed with $\mathrm{BCa}$ in Ontario during fiscal years 2012-2015, among whom 30,426 had a known BCa subtype. The distribution by subtype was $64.8 \%$ HR+, HER2-; $14.3 \%$ HER $2+$; and $9.5 \%$ had TNBC. The subtype for remaining $11.4 \%$ was unknown. A study by Fallahpour and colleagues ${ }^{28}$ reported similar subtype distributions (59.0\% HR+, HER 2-; $11.7 \%$ HER $2+$; and $8.6 \%$ TNBC) in Ontario between 2010 and 2012, but the proportion of patients with an unknown BCa subtype in their study (20.6\%) was higher than that reported here. Other epidemiologic studies from England $(5.3 \% \text { TNBC })^{29}$, France $(66.8 \%$ HR+, HER $2-; 10.0 \%$ HER $2+; 6.3 \%$ TNBC; $14.0 \%$ unspecified ${ }^{30}$, and the United 

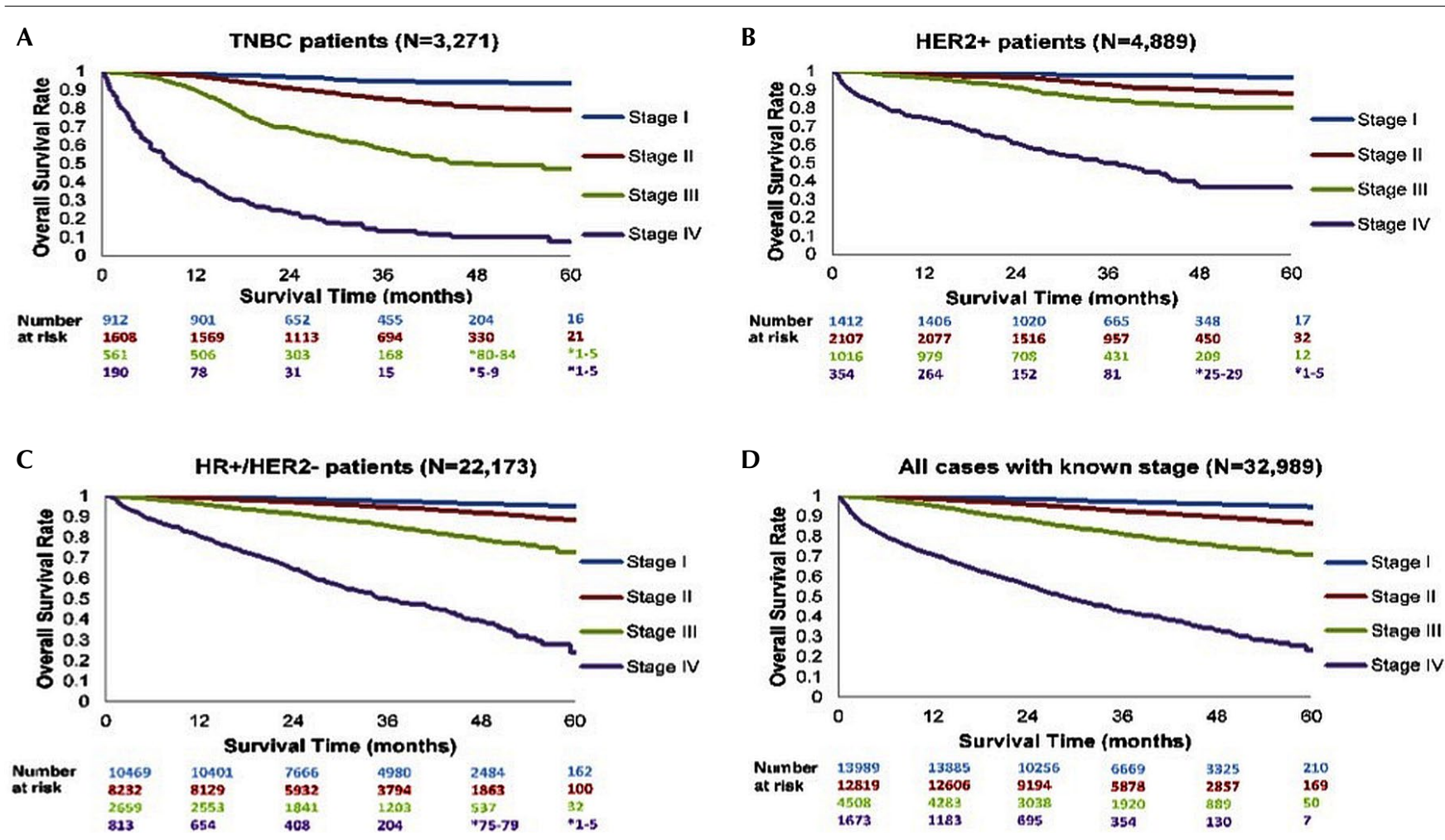

FIGURE 2 Kaplan-Meier survival estimates overall and by subtype for cases of breast cancer with a known stage. TNBC = triple negative breast cancer; HER2 = human epidermal growth factor receptor 2; HR = hormone receptor.

States (66.6\% HR+, HER2-; $14.0 \%$ HER $2+; 10.8 \%$ TNBC; $8.7 \%$ unspecified ${ }^{31}$ also yielded similar subtype distributions. Thus, the distribution of BCa subtypes observed in the present study is similar to those in other real-world epidemiology studies. Similarly, the incidence per 100,000 by BCa subtype reported here is consistent with other smaller Canadian cohort studies ${ }^{28,32}$ and a study conducted in England ${ }^{33}$.

Our study revealed poor survival for women with highstage TNBC, as did an analysis by Dent and colleagues ${ }^{34}$. However, variation in recurrence and survival outcomes by stage for patients with TNBC has been reported in the literature. For example, a large retrospective study $(n=1879)$ of surgical patients with $\mathrm{BCa}$, which had a median follow-up of 73.3 months, observed no relationship between TNM staging and recurrence-free survival for patients with $\mathrm{TNBC}^{35}$. Reddy and colleagues ${ }^{36}$ recently reported on the risk of late recurrence in 873 patients with early stage TNBC who were disease-free at least 5 years after diagnosis, with a median follow-up of 8.3 years. In that group, the 10 -year recurrence-free survival was $91 \%$. The natural history of TNBC thus differs significantly from that of $\mathrm{HR}+\mathrm{BCa}$, which portends a persistent risk of recurrence up to 20 years after diagnosis despite adjuvant endocrine therapy ${ }^{37-39}$.

Patients with metastatic TNBC have consistently been shown to experience survival inferior to that experienced by patients with other metastatic BCa subtypes ${ }^{20,36,40-44}$. Of 7578 women in the Surveillance, Epidemiology, and End Results database study ${ }^{20}$ diagnosed with stage IV BCa between 2010 and 2013, 13.2\% had TNBC and experienced a mos of 13.0 months (95\% confidence interval: 12.2 months to 13.8 months). The younger median age of the patients and the inclusion of those with prior early (nonmetastatic) BCa might explain the slightly longer mos in the Surveillance, Epidemiology, and End Results cohort compared with our cohort. We acknowledge, however, that some Canadian data suggest longer mos for patients with de novo metastatic TNBC than for those with metastatic relapse $\mathrm{e}^{40}$ (11 months vs. 8 months, $p=0.02$ ). Kassam and colleagues ${ }^{41}$ also conducted a retrospective cohort study of 111 patients with metastatic TNBC at 3 University of Toronto-affiliated institutions between January 2003 and December 2006; the mos in that cohort was 13.3 months (range: $0.8-99.8$ months). Inherent bias toward the selection of generally healthy patients who present for treatment to a cancer centre likely resulted in longer mos, albeit the very small sample size that represented a limitation in that retrospective study. A different distribution of molecular TNBC subtypes in the various studies (something that was not assessed in our study) might also contribute to differences in reported clinical outcomes ${ }^{45}$.

The poor survival of patients with metastatic TNBC might be attributable to biologically aggressive disease, with a propensity for metastases to visceral organs and the central nervous system ${ }^{46-48}$. A lack of effective and targeted treatment options also contributes to poor outcomes for women with metastatic TNBC. However, immunotherapy $^{42}$, poly-ADP ribose polymerase inhibitors ${ }^{49,50}$, the AKT inhibitors ipatasertib ${ }^{51}$ and capivasertib ${ }^{52}$, and antibodydrug conjugates such as sacituzumab govitecan-hziy ${ }^{53}$ 
in development for metastatic TNBC all hold promise for improved outcomes in that subgroup.

In our study, the mos was longest among women with HER2+ metastatic breast cancer (37.3 months), which is shorter than the mos of 56.5 months observed in the firstline trial of paclitaxel and trastuzumab with or without pertuzumab ${ }^{54}$. Our shorter os might reflect the inclusion of women in the "real world" setting and the limited use of trastuzumab emtansine in the second-line setting in the cohort (approved by Health Canada in 2013 and funded as of May 2014); however, treatment patterns are beyond the scope of this manuscript.

Finally, the mos for women with HR+, HER2- metastatic BCa was 35.2 months at a time when single-agent endocrine therapy was typically used in the first-line metastatic setting. It is likely that the outcomes of women with HR+, HER2breast cancer will improve over time with the increasing uptake of inhibitors of cyclin-dependent kinases 4 and 6 and of PI3K, which have been associated with a clinically meaningful benefit in this subtype ${ }^{55-57}$.

Whether patients with HR+, HER $2+$ BCa as opposed to HR-, HER2 + BCa have superior outcomes has been debated, with several studies reporting conflicting clinical results ${ }^{58,59}$. We did not distinguish between $\mathrm{HR}+$ and $\mathrm{HR}-$ status for the population of women with HER2+ tumours; that difference could be explored in future publications.

The present Canadian cohort study is one of the largest to date spanning multiple years, allowing 30,426 women with BCa of a known subtype to be analyzed for annual incidence and 32,989 women with BCa of known disease stage at diagnosis to be analyzed for os. The study has some limitations, such including only women resident in Ontario, excluding the $11 \%$ of women with an unknown BCa subtype, incomplete assessment of performance status, and lack of other biomarker results (Ki-67, epidermal growth factor receptor, cytokeratin 7 ). In addition, mos could be calculated only for women with stage IV disease and those for whom relapse or recurrence could not be assessed. Given the variation in the natural history of $\mathrm{BCa}$, it would be of great interest to examine, at a future date, early and late recurrence by disease subtype in Canadian women ${ }^{24,44-46}$.

\section{CONCLUSIONS}

This retrospective, population-based study of 30,426 women with $\mathrm{BCa}$ is the largest Canadian $\mathrm{BCa}$ cohort to date, revealing a subtype distribution consistent with previously reported data, together with comparable patterns of annual incidence and os. The significantly shorter survival observed for women with advanced disease, particularly metastatic TNBC, highlights the pressing need to provide better treatment options. Future work will include an examination of treatment patterns and resource costs associated with each вCa subtype to better understand disease management and the impact of BCa in Canada.

\section{ACKNOWLEDGMENTS}

This study made use of de-identified data from the ICES Data Repository, which is managed by ICES with support from its funders and partners: Canada's Strategy for Patient-Oriented Research (SPOR), the Ontario SPOR SUPPORT Unit, the Canadian Institutes of
Health Research, and the Government of Ontario. The opinions, results, and conclusions reported are those of the authors. No endorsement by ICES or any of its funders or partners is intended or should be inferred. Parts of this material are based on data and information compiled and provided by Canadian Institute for Health Information (CIHI). However, the analyses, conclusions, opinions, and statements expressed herein are those of the authors, and not necessarily those of CIHI. Parts of this material are based on data and information provided by Ontario Health (Cancer Care Ontario) [OH(CCO)]. The opinions, results, views, and conclusions reported in this paper are those of the authors and do not necessarily reflect those of $\mathrm{OH}(\mathrm{CCO})$. No endorsement by $\mathrm{OH}(\mathrm{CCO})$ is intended or should be inferred.

The authors also thank Shazia Hassan, Cloris Xue, and Aleksa Miladinovic for manuscript assistance.

\section{CONFLICT OF INTEREST DISCLOSURES}

We have read and understood Current Oncology's policy on disclosing conflicts of interest, and we declare the following interests: SJS declares consultancies through the HOPE Research Centre, a group that consults to the pharmaceutical industry. Medical writing support was received from Hoffmann-La Roche Limited. BP, KEF, and MC are employees of Hoffmann-La Roche Limited. KJJ declares consultancies with Esai, Genomic Health Inc., Novartis, Purdue Pharma, Pfizer, and Roche. She has also received grants or research support from AstraZeneca and speaker fees from Apobiologix, Novartis, and Purdue Pharma.

\section{AUTHOR AFFILIATIONS}

*HOPE Research Centre, Sunnybrook Research Institute, Toronto, $\mathrm{ON}$; ${ }^{\dagger}$ Department of Medical Affairs and ${ }^{\ddagger}$ Market Access and Pricing Department, Hoffmann-La Roche Limited, Mississauga, ON; ${ }^{\S}$ Odette Cancer Centre, Sunnybrook Health Sciences Centre, Toronto, ON.

\section{REFERENCES}

1. Canadian Cancer Society. Breast Cancer Statistics [Web page]. Toronto, ON: Canadian Cancer Society; 2018. [Available at: http://www.cancer.ca/en/cancer-information/cancer-type/ breast/statistics/?region=on; cited 21 February 2019]

2. Perou CM, Sorlie T, Eisen MB, et al. Molecular portraits of human breast tumours. Nature 2000;406:747-52.

3. Fan C, Oh DS, Wessels L, et al. Concordance among gene-expression-based predictors for breast cancer. $N$ Engl JMed 2006;355:560-9.

4. Zaha DC. Significance of immunohistochemistry in breast cancer. World J Clin Oncol 2014;5:382-92.

5. Guiu S, Michiels S, Andre F, et al. Molecular sub-classes of breast cancer: how do we define them? The IMPAKT 2012 Working Group statement. Ann Oncol 2012;23:2997-3006.

6. Rivenbark AG, O'Connor SM, Coleman WB. Molecular and cellular heterogeneity in breast cancer: challenges for personalized medicine. Am J Pathol 2013;183:1113-24.

7. Goldhirsch A, Winer EP, Coates AS, et al. on behalf of the panel members. Personalizing the treatment of women with early breast cancer: highlights of the St Gallen International Expert Consensus on the primary therapy of early breast cancer. Ann Oncol 2013;24:2206-23.

8. Yersal O, Barutca S. Biological subtypes of breast cancer: prognostic and therapeutic implications. World J Clin Oncol 2014;5:412-24.

9. Dai X, Li T, Bai Z, et al. Breast cancer intrinsic subtype classification, clinical use and future trends. Am J Cancer Res 2015; 5:2929-43.

10. Engstrom MJ, Opdahl S, Hagen AI, et al. Molecular subtypes, histopathological grade and survival in a historic cohort of breast cancer patients. Breast Cancer Res Treat2013;140:463-73. 
11. Sheridan $\mathrm{W}, \mathrm{S} \operatorname{cott} \mathrm{T}$, Caroline $\mathrm{S}$, et al. Breast cancer in young women: have the prognostic implications of breast cancer subtypes changed overtime? Breast Cancer Res Treat 2014; 147:617-29.

12. Parise CA, Caggiano V. Breast cancer survival defined by the ER/PR/HER2 subtypes and a surrogate classification according to tumor grade and immunohistochemical biomarkers. J Cancer Epidemiol 2014;2014:469251.

13. Kohler BA, Sherman RL, Howlader N, et al. Annual report to the nation on the status of cancer, 1975-2011, featuring incidence of breast cancer subtypes by race/ethnicity, poverty, and state. J Natl Cancer Inst 2015;107:djv048.

14. Wolff AC, Hammond ME, Schwartz JN, et al. on behalf of the American Society of Clinical Oncology and the College of American Pathologists. American Society of Clinical Oncology/College of American Pathologists guideline recommendations for human epidermal growth factor receptor 2 testing in breast cancer. J Clin Oncol 2007;25:118-45.

15. Chia S, Norris B, Speers C, et al. Human epidermal growth factor receptor 2 overexpression as a prognostic factor in a large tissue microarray series of node-negative breast cancers. J Clin Oncol 2008;26:5697-704.

16. Ross JS, Slodkowska EA, Symmans WF, Pusztai L, Ravdin PM, Hortobagyi GN. The HER-2 receptor and breast cancer: ten years of targeted anti-HER-2 therapy and personalized medicine. Oncologist 2009;14:320-68.

17. Davies C, Godwin J, Gray R, et al. on behalf of the Early Breast Cancer Trialists' Collaborative. Relevance of breast cancer hormone receptors and other factors to the efficacy of adjuvant tamoxifen: patient-level meta-analysis of randomised trials. Lancet 2011;378:771-84.

18. Kaplan HG, Malmgren JA. Impact of triple negative phenotype on breast cancer prognosis. Breast J 2008;14:456-63.

19. Grann VR, Troxel AB, Zojwalla NJ, Jacobson JS, Hershman D, Neugut AI. Hormone receptor status and survival in a population-based cohort of patients with breast carcinoma. Cancer 2005;103:2241-51.

20. Gong Y, Liu YR, Ji P, Hu X, Shao ZM. Impact of molecular subtypes on metastatic breast cancer patients: a SEER population-based study. Sci Rep 2017;7:45411.

21. Giordano SH, Temin S, Chandarlapaty S, et al. Systemic therapy for patients with advanced human epidermal growth factor receptor 2-positive breast cancer: ASCO clinical practice guideline update. J Clin Oncol 2018;36:2736-40.

22. Cronin KA, Harlan LC, Dodd KW, Abrams JS, Ballard-Barbash R. Population-based estimate of the prevalence of HER-2 positive breast cancer tumors for early stage patients in the US. Cancer Invest 2010;28:963-8.

23. Carey L, Dees E, Sawyer L, et al. The triple negative paradox: primary tumor chemosensitivity of breast cancer subtypes. Clin Cancer Res 2007;13:2329-34.

24. Haque R, Ahmed SA, Inzhakova G, et al. Impact of breast cancer subtypes and treatment on survival: an analysis spanning two decades. Cancer Epidemiol Biomarkers Prev 2012; 21:1848-55.

25. Ontario Health (Cancer Care Ontario) [OH(CCO)]. Ontario Cancer Statistics 2018. Estimated Current Cancer Mortality. Toronto, ON: $\mathrm{OH}(\mathrm{CCO}) ; 2018$. [Available online at: https://www. cancercareontario.ca/sites/ccocancercare/files/assets/ OCS2018Chapter2_2.pdf; cited 5 December 2018]

26. Hammond MEH, Hayes DF, Dowsett M, et al. on behalf of the American Society of Clinical Oncology and the College of American Pathologists. American Society of Clinical Oncology/College of American Pathologists guideline recommendations for immunohistochemical testing of estrogen progesterone receptors in breast cancer. Arch Pathol Lab Med 2010;134:e48-72.
27. Quan H, Li B, Couris CM, et al. Updating and validating the Charlson comorbidity index and score for risk adjustment in hospital discharge abstracts using data from 6 countries. Am J Epidemiol 2011;173:676-82.

28. Fallahpour S, Navaneelan T, De P, Borgo A. Breast cancer survival by molecular subtype: a population-based analysis of cancer registry data. CMAJ Open 2017;5:E734-9.

29. Jack RH, Davies EA, Renshaw C, et al. Differences in breast cancer hormone receptor status in ethnic groups: a London population. Eur J Cancer 2013;49:696-702.

30. Cortet M, Bertaut A, Molinié F, et al. Trends in molecular subtypes of breast cancer: description of incidence rates between 2007 and 2012 from three French registries. BMC Cancer 2018;18:161.

31. Howlader N, Cronin KA, Kurian AW, Andridge R. Differences in breast cancer survival by molecular subtypes in the United States. Cancer Epidemiol Biomarkers Prev 2018;27:619-26.

32. Hammond E, Shu E, Sawchuk K, et al. Population-based analysis of breast cancer treatment by intrinsic sub-type in Manitoba, Canada. Cancer Epidemiol 2016;45:82-90.

33. United Kingdom, Office for National Statistics (ONS). Cancer registration statistics, England: 2016 [Web page]. London, U.K.: ONS; 2018. [Available at: https://www.ons.gov.uk/releases/ cancerregistrationstatisticsengland2016; cited 11 December 2018]

34. Dent R, Trudeau M, Pritchard KI, et al. Triple-negative breast cancer: clinical features and patterns of recurrence. Clin Cancer Res 2007;13:4429-34.

35. Park YH, Lee SJ, Cho EY, et al. Clinical relevance of TNM staging system according to breast cancer subtypes. Ann Oncol 2011;22:1554-60. [Erratum in:Ann Oncol 2019;30:2011]

36. Reddy SM, Barcenas $\mathrm{CH}$, Sinha AK, et al. Long-term survival outcomes of triple-receptor negative breast cancer survivors who are disease free at 5 years and relationship with low hormone receptor positivity. Br J Cancer 2018;118:17-23.

37. Ingle JN, Tu D, Pater JL, et al. Intent-to-treat analysis of the placebo-controlled trial of letrozole for extended adjuvant therapy in early breast cancer: NCIC CTG MA.17. Ann Oncol 2008;19:877-82.

38. Cuzick J, Sestak I, Baum M, et al. on behalf of the ATAC/LATTE investigators. Effect of anastrozole and tamoxifen as adjuvant treatment for early-stage breast cancer: 10-year analysis of the ATAC trial. Lancet Oncol 2010;11:1135-41.

39. Pan H, Gray RG, Davies C, et al. Predictors of recurrence during years 5-14 in 46,138 women with ER+ breast cancer allocated 5 years only of endocrine therapy [abstract 505]. J Clin Oncol 2016;34:. [Available online at: https://ascopubs. org/doi/abs/10.1200/JCO.2016.34.15_suppl.505; cited 10 April 2020]

40. den Brok WD, Speers CH, Gondara L, Baxter E, Tyldesley SK, Lohrisch CA. Survival with metastatic breast cancer based on initial presentation, de novo versus relapsed. Breast Cancer Res Treat 2017;161:549-56.

41. Kassam F, Enright K, Dent R, et al. Survival outcomes for patients with metastatic triple-negative breast cancer: implication for clinical practice and trial design. Clin Breast Cancer 2009;9:29-33.

42. Schmid P, Adams S, Rugo HS, et al. on behalf of the IMpassion130 trial investigators. Atezolizumab and nab-paclitaxel in advanced triple-negative breast cancer. $N$ Engl J Med 2018;379:2108-21.

43. Urru SAM, Gallus S, Bosetti C, et al. Clinical and pathological factors influencing survival in a large cohort of triplenegative breast cancer patients. BMC Cancer 2018;18:56.

44. LeVasseur N, Fiorino L, Speers CH, Aparicio M, Lohrisch C, Chia SK. Prognosis and survival in metastatic breast cancerten years in review, a population-based analysis [abstract 
P1-16-05]. Cancer Res 2019;79(suppl):. [Available online at: http://cancerres.aacrjournals.org/content/79/4_Supplement/ P1-16-05; cited: 2 July 2019]

45. Sharma P, Barlow WB, Hout DR, et al. Impact of molecular subtypes on long-term outcomes in triple-negative breast cancer (TNBC) patients treated with adjuvant AC chemotherapy on swog S9313 [abstract P4-08-06]. Cancer Res 2019;79 (suppl):. [Available online at: http://www.insightgenetics. com/sm_files/SABCS_2018_Sharma_Poster_P40806.pdf; cited 10 April 2020]

46. Liedtke C, Mazouni C, Hess KR, et al. Response to neoadjuvant therapy and long-term survival in patients with triple-negative breast cancer. J Clin Oncol 2008;26:1275-81.

47. Carey LA, Dees EC, Sawyer L, et al. The triple negative paradox: primary tumor chemosensitivity of breast cancer subtypes. Clin Cancer Res 2007;13:2329-34.

48. Haffty BG, Yang Q, Reiss M, et al. Locoregional relapse and distant metastasis in conservatively managed triple negative early-stage breast cancer. J Clin Oncol 2006;24:5652-7.

49. Litton JK, Rugo HS, Ettl J, et al. Talazoparib in patients with advanced breast cancer and a germline BRCA mutation. N Engl J Med 2018;379:753-63.

50. Robson M, Im SA, Senkus E, et al. Olaparib for metastatic breast cancer in patients with a germline BRCA mutation. $N$ Engl J Med 2017;377:523-33. [Erratum in: $N$ Engl J Med 2017;377:1700]

51. Kim SB, Dent R, Im SA, et al. on behalf of the LotUs investigators. Ipatasertib plus paclitaxel versus placebo plus paclitaxel as first-line therapy for metastatic triple-negative breast cancer
(LOTUS): a multicentre, randomised, double-blind, placebocontrolled, phase 2 trial. Lancet Oncol 2017;18:1360-72.

52. Rinnerthaler G, Gampenrieder SP, Greil R. ASCO 2018 highlights: metastatic breast cancer. 2018;11:276-9.

53. BardiaA, MayerIA, VahdatLT, etal.Sacituzumabgovitecan-hziy in refractory metastatic triple-negative breast cancer. $N E n g l$ J Med 2019;380:741-51.

54. Swain SM, Baselga J, Sung-Bae K, et al. Pertuzumab, trastuzumab, and docetaxel in HER2-positive metastatic breast cancer. N Engl J Med 2015;372:724-34.

55. Turner NC, Slamon DJ, Ro J, et al. Overall survival with palbociclib and fulvestrant in advanced breast cancer. $N \mathrm{EnglJ}$ Med 2018;379:1926-36.

56. Hurvitz SA, Im SA, Lu YS, et al. Phase III MONALEESA-7 trial of premenopausal patients with HR+/HER- advanced breast cancer $(\mathrm{ABC})$ treated with endocrine therapy $+/$ - ribociclib: overall survival (OS) results [abstract LBA1008]. J Clin Oncol 2019;37:. [Available online at: https://meetinglibrary.asco. org/record/174827/abstract; cited 10 April 2020]

57. Stirrups R. Alpelisib plus fulvestrant for PIK3CA-mutated breast cancer. Lancet Oncol 2019;20:e347.

58. Leone JP, Leone J, Zwenger AO, Vallejo CT, Leone BA. Prognostic significance of tumor subtypes in women with breast cancer according to stage: a population-based study. $\mathrm{Am} \mathrm{J}$ Clin Oncol 2019:42:588-95.

59. Chumsri S, Li Z, Serie DJ, et al. Incidence of late relapses in patients with HER2-positive breast cancer receiving adjuvant trastuzumab: combined analysis of NCCTG N9831 (Alliance) and NRG Oncology/NSABP B-31. J Clin Oncol 2019;37:3425-35. 